Article

\title{
Srebf2 Locus Overexpression Reduces Body Weight, Total Cholesterol and Glucose Levels in Mice Fed with Two Different Diets
}

\author{
Irene Andrés-Blasco ${ }^{1}$, Sebastian Blesa ${ }^{1}$, Ángela Vinué ${ }^{2}$, Herminia González-Navarro ${ }^{2,3}$, \\ José Tomás Real ${ }^{2,3,4,5}$, Sergio Martínez-Hervás ${ }^{2,3,4,5} \mathbb{D}$, Julián Carretero ${ }^{6}$, \\ Antonio Ferrández-Izquierdo 2,7,8, Felipe Javier Chaves 1,3,* and Ana-Bárbara García-García 1,3 (D) \\ 1 Genomics and Diabetes Unit, Health Research Institute Clinic Hospital of Valencia-INCLIVA, \\ Menendez Pelayo 4acc, 46010 Valencia, Spain; iranbla@gmail.com (I.A.-B.); sebastian.blesa@ext.uv.es (S.B.) \\ 2 Health Research Institute Clinic Hospital of Valencia-INCLIVA, 46010 Valencia, Spain; \\ m.angela.vinue@uv.es (Á.V.); Herminia.Gonzalez@uv.es (H.G.-N.); Antonio.ferrandez@uv.es (A.F.-I.) \\ 3 CIBERDEM (Diabetes and Associated Metabolic Diseases), 28029 Madrid, Spain; a.barbara.garcia@ext.uv.es \\ 4 Endocrinology and Nutrition Service, Clinic Hospital of Valencia, 46010 Valencia, Spain; \\ jose.t.real@uv.es (J.T.R.); Sergio.martinez@uv.es (S.M.-H.) \\ 5 Department of Medicine, University of Valencia, 46010 Valencia, Spain \\ 6 Department of Physiology, University of Valencia, 46010 Valencia, Spain; julian.carretero@uv.es \\ 7 Pathology Service, Clinic Hospital of Valencia, 46010 Valencia, Spain \\ 8 Department of Pathology, University of Valencia, 46010 Valencia, Spain \\ * Correspondence: felipe.chaves@uv.es; Tel.: +34-96-3864100 (ext. 81905)
}

Received: 22 September 2020; Accepted: 10 October 2020; Published: 14 October 2020

\begin{abstract}
Macronutrients represent risk factors for hyperlipidemia or diabetes. Lipid alterations and type 2 diabetes mellitus are global health problems. Overexpression of sterol regulatory element-binding factor (Srebf2) in transgenic animals is linked to elevated cholesterol levels and diabetes development. We investigated the impact of increased Srebf2 locus expression and the effects of control and high-fat, high-sucrose (HFHS) diets on body weight, glucose and lipid metabolisms in transgenic mice (S-mice). Wild type (WT) and S-mice were fed with both diets for 16 weeks. Plasma glucose, insulin and lipids were assessed $(n=25)$. Immunostainings were performed in liver, pancreas and fat $(\mathrm{N}=10)$. Expression of $L d l r$ and $H m g c r$ in liver was performed by RT-PCR $(\mathrm{N}=8)$. Control diet: S-mice showed reduced weight, insulin, total and HDL cholesterol and triglycerides (TG). HFHS diet widened differences in weight, total and HDL cholesterol, insulin and HOMA index but increased TG in S-mice. In S-mice, adipocyte size was lower while HFHS diet produced lower increase, pancreatic $\beta$-cell mass was lower with both diets and Srebf2, Ldlr and Hmgcr mRNA levels were higher while HFHS diet produced a rise in Srebf2 and Hmgcr levels. Srebf 2 complete gene overexpression seems to have beneficial effects on metabolic parameters and to protect against HFHS diet effects.
\end{abstract}

Keywords: cholesterol; atherosclerosis; lipoproteins; sterol regulatory element-binding protein 2 (SREBP-2); carbohydrate metabolism; lipid metabolism; high-fat; high-sucrose diet; transgenic mice

\section{Introduction}

Metabolic alterations, mainly lipid metabolism disorders (LMD) and type 2 diabetes mellitus (T2DM), constitute a major global health problem according to the World Health Organization (WHO). There has been a fast increment in their incidence due to unhealthy lifestyle habits (sedentariness, excessive caloric intake), population ageing and genetic and epigenetic factors [1]. The lifespan of 
patients with these diseases is shorter compared to the general population [2]. The intake of a high-fat diet can lead to diet-induced obesity and metabolic disorders in humans that can be induced in the same way in rodents.

In order to understand the effects of macronutrients in humans, it is important to consider their effects in mice (including the analysis in lean as well as obese ones) to clarify the pathogenesis of the metabolic disorders [3-5]. The sterol regulatory element-binding protein (SREBP) system is one of the main regulators of body and cellular metabolism [6].

SREBPs precursors are inserted into the endoplasmic reticulum (ER). They contain two membrane-spanning domains responsible for this insertion. This form is inactive and cannot undergo transcription. SCAP (or SREBP-cleavage-activating protein) interacts with the C-terminal SREBPs domain and as a result SREBPs move from the ER to the Golgi. This SCAP-SREBPs interaction takes place when cells are sterol-depleted. Due to the action of two Golgi proteases (site 1 and site 2 proteases, or S1P and S2P), the mature and transcriptionally active SREBPs forms are released. (Supplementary Figure S1) Mature SREBPs forms are translocated to the nucleus and join to the SREBPs target genes promoters [7]. SREBPs are transcription factors involved in cholesterol, lipid and glucose metabolism [7]. They also participate in adipocyte differentiation and insulin-dependent gene expression $[6,8]$.

The SREBP system as a whole has been associated with different diseases such as dyslipidaemia, obesity, blood pressure, insulin resistance, diabetes mellitus, non-alcoholic fatty liver disease, nonalcoholic steatohepatitis, and chronic kidney disease [6,9-14].

SREBP system regulation is complex; recent studies have shown that SREBP-2 activity regulates SREBF1c and SREBF1a in the liver, implying that SREBP-2 could modulate the function of the whole system [15]. Studies using transgenic animals have shown that increased truncated SREBP-2, without a regulatory domain, can lead to alteration of insulin secretion, lower pancreatic $\beta$-cell (PBC) count, diabetes, reduced fat reserves, lower weight, increased total cholesterol in blood and tissues, and non-alcoholic hepatic steatosis [6]. In humans, some studies associate SREBF2 variants with hypercholesterolemia [16], insulin resistance, DM and liver steatosis [17]. The SREBF2 gene contains miR-33a gene which has been related to gene regulation in relation to cholesterol synthesis and efflux, insulin secretion and metabolism [18-21].

The present study has investigated the effect of increased Srebf2 locus expression on glucose homeostasis and lipid metabolism in mice, and the effect of control and high-fat-high-sucrose diet (HFHS). To this end, we generated a transgenic mouse (S-mouse) with limited overexpression of the normal SREBP-2 protein by including extra copies of the Srebf2 locus (which therefore includes miR-33a, which is located in intron 16 of Srebf2) controlled by its own promoter. Our S-mouse could prove a useful model to study the effect of treatments regulating Srebf2 gene expression (including miR-33a) and/or SREBP-2 activity.

\section{Materials and Methods}

\subsection{Mice and Diets}

Animal care complied with institutional guidelines and following the 2010/63/EU European Parliament directive. All experiments were approved by the Animal Ethics Committee of Valencia University. Animals were transfected by microinjection with a pStart-K vector containing the Srebf2 mouse gene (pStart-K-mSrebf2) from BAC MGSCv37 C57BL/6J (vector from mouse chromosome 15 including Srebf 2 gene and 10 upstream and 5 downstream $\mathrm{Kb}$ (Cyagen, Santa Clara, CA, USA). Therefore, transgenic SREBP-2 mice (S-mice) used in this study carried extra copies of Srebf2 gene, including the $5^{\prime}$ and $3^{\prime}$ indicated regions. A scheme of the cloning strategy and vector used can be seen in Supplementary Figure S2. Transgenic mice were obtained after backcrosses into C57BL/6J background. Wild type (WT) C57BL/6J mice (Charles River Laboratories, Wilmington, MA, USA) were used as a control group. The introduction of the extra copy of the Srebf2 gene was verified by quantitative PCR (data not shown) in both groups. Both groups were identified by genotyping to detect or not presence 
of the vector regions (one primer hybridizes in the part of the vector that is inserted and other in a close regions of the inserted mouse genetic region: Srebf2-1: ATTGCTAGGCTCCCATTCCAA and vector: TGAAGTCAGCCCCATACGAT) and by the analysis of the extra Srebf2 copy by EOSAL-CNV [22], data not shown). Mice had access to food and water ad libitum and were exposed to a 12-h light-dark cycle. Mice were maintained on a control diet (Teklad Global 14\% Protein Rodent Maintenance Diet, Envigo, Indianapolis, IN, USA) and at 8 weeks of age, male and female S-mice and WT mice were placed on a HFHS diet for 16 weeks (60\% fat $24 \%$ sucrose. Ssniff, Spezialdiäten, Soest, Germany). The diets compositions are detailed in Supplementary Table S1. Other control groups (male and female S-mice and WT mice) were bred and kept on a control diet for 24 weeks in the same animal facility.

\subsection{Food Intake Experiment}

For evaluation of food intake experiments mice were separated into individual cages at least 2 days prior to experiments. The animals were separated according to sex and genotype. For determination of daily food intake mice were fed a known amount of control diet and the remaining food was measured after $48 \mathrm{~h}$. The experiment was repeated three times with the same animals.

\subsection{Metabolic Measurements}

Measurement of levels of plasma triglycerides (TG), total cholesterol (TC) and non-esterified fatty acids (NEFAs) was performed in overnight-fasted mice with standard enzymatic procedures using, respectively, LabAssay ${ }^{\mathrm{TM}}$ Triglyceride (reference 290-63701), LabAssay ${ }^{\mathrm{TM}}$ Cholesterol (reference 290-63701) (FUJIFILM Wako Chemicals, Neuss, Germany), and Free Fatty Acid Quantitation Kit (reference MAK044-1KT, Merck KGaA, Darmstadt, Germany).

HDL-cholesterol (HDL-C) was determined after dextran sulphate/ $\mathrm{MgCl}_{2}$ precipitation of the apolipoprotein B-containing lipoproteins [23] (Dextran sulfate sodium salt, reference 42867-5G Merck KGaA) using the LabAssay ${ }^{\mathrm{TM}}$ Cholesterol (reference 290-63701) (FUJIFILM Wako Chemicals)

The glucose tolerance test (GTT) was performed as follows: after fasting overnight, an intraperitoneal injection of glucose solution ( $2 \mathrm{~g} / \mathrm{Kg}$ of body weight, BW) was given to mice (reference 49163, Merck KGaA). Analysis of plasma glucose and insulin was performed at different times with an Ascensia Elite glucometer (Bayer AG, Leverkusen, Germany) and an ELISA ultrasensitive anti-mouse insulin, respectively (reference 90080, Crystal Chem, Zaandam, the Netherlands) [24,25].

For the insulin tolerance test (ITT), mice fasted for $4 \mathrm{~h}$. They were given an intraperitoneal insulin injection (0.5 U/Kg of BW (ACTRAPID, EAN: 8470007755029, NovoNordisk, Copenhagen, Denmark), and plasma glucose levels were measured as explained above.

To analyze insulin resistance (IR), HOMA-IR index was calculated applying the formula "fasting plasma glucose $(\mathrm{mmol} / \mathrm{L}) \times$ fasting plasma insulin $(\mu \mathrm{IU} / \mathrm{mL}) / 22.5^{\prime \prime}$.

Determination of liver TG content was performed after tissue digestion and saponification in ethanolic potassium hydroxide followed and enzymatic measurement of glycerol content (Free Glycerol Reagent, reference F6428, Merck KGaA) [26].

\subsection{Enzyme-Linked Immuno Sorbent Assay (ELISA)}

Insulin levels were determined in isolated plasma from ethylenediamine tetraacetic acid (EDTA) disodium salt dihydrate blood (reference 324503, Merck KGaA, Darmstadt, Germany) from mice using an Ultrasensitive Mouse Insulin ELISA kit (reference 90080, Crystal Chem). The kit was used following the manufacturer's instructions.

\subsection{Liver, Pancreas and Fat Immunostainings}

For immunohistopathological analysis, liver, pancreas and fat were sectioned from mice sacrificed by cervical dislocation after perfusion with PBS, and then fixed with $4 \%$ paraformaldehyde/PBS for $4 \mathrm{~h}$ and paraffin embedded. $\beta$-cell mass was calculated by two ways: area of pancreatic islets relative to total pancreatic area (\%), and pancreatic islet number relative to pancreatic area. Identification 
of pancreatic islet was undergone by insulin immunostaining in 3-4 slides per mouse, separated by $125 \mu \mathrm{m}$.

The immunohistochemistry protocol consisted of incubation with primary antibody (mouse monoclonal anti-insulin 1/500 dilution, reference I2018, Merck KGaA) followed by biotinylated anti-mouse secondary antibody (1/300 dilution, reference sc-2039, Santa Cruz Biotecnology Inc., Dallas, TX, USA), streptavidin-HRP 1/2 dilution (reference TS-060-HR, Thermo Fisher Scientific Inc., Waltham, MA, USA) and DAB substrate (reference SK4100, Vector Laboratories, Burlingame, CA, USA). Slides were counterstained with haematoxylin and mounted with EUKITT (reference A10500, Deltalab, Barcelona, Spain). Images were captured with a digital stereo microscope with micro imaging LEICA DMD108 (Leica Biosystems, Wetzlar, Germany) and analyzed by computer-assisted morphometry with Image J (1.47v, NIH, available at https://imagej.nih.gov/ij/download.html). Lipid droplet content in liver and adipocyte content in fat was performed in haematoxylin-eosin stained section.

\subsection{Adipocyte Quantification in Adipose Tissue: Size and Number}

Adipocyte quantification in fat was performed in haematoxylin stained sections and analyzed by computer-assisted morphometry with Image J (1.47v, NIH, available at https://imagej.nih.gov/ ij/download.html). Images were transformed from RGB to HSV color space with MRI adipocyte tools. To allow the application of standard morphological operations the image was then binarized. Adipocytes were counted, and absolute pixel area of each object was calculated and converted to $\mu \mathrm{m}^{2}$ [27]. The number and size of adipocytes were calculated and added to give values per animal.

\subsection{RNA Extraction and Reverse Transcription from Tissue Samples}

Total RNA from mouse liver was obtained using the Maxwell ${ }^{\circledR} 16$ miRNA Tissue Kit (reference AS1470, Promega, Madison, WI, USA). This kit allows the extraction of total RNA with enriched miRNA. The extraction kit was used according to the manufacturer's instructions including the elution volumes quoted. RNA concentration and purity were measured using the NanoDrop ND-1000 spectrophotometer (Thermo Fisher Scientific Inc.) using $2 \mu \mathrm{L}$ of RNA. RNA purity was evaluated using absorbance 260/absorbance 280 ratio: Ratios between 1.8 and 2.0 were assumed to be pure. All RNA samples were kept at $-80^{\circ} \mathrm{C}$. To obtain cDNA, $500 \mathrm{ng}$ of RNA per sample was reverse transcribed with Ready-To-Go You-Prime First-Strand Beads kit (reference 27926401, Cytiva, Marlborough, MA, USA). cDNA was diluted 1:10 in nuclease-free water and were stored at $-20{ }^{\circ} \mathrm{C}$.

\section{8. mRNA Quantification by Real-Time Quantitative PCR}

$2 \mu \mathrm{L}$ of diluted cDNA were used to perform the real-time quantification PCR using a 480 II real-time PCR system (Roche, Basel, Switzerland). The Kapa Sybr Fast qPCR master mix (reference KK4601 Roche) was used and all reactions were run in triplicate following manufacturer's protocol, including blank/negative controls without cDNA. Data were analyzed with the apparatus software (version 1.5, LightCycler ${ }^{\circledR} 480$ Software, reference 04994884001, Roche, Switzerland), determining the threshold cycle $(\mathrm{Ct})$ and the average of each sample. Concentrations of mRNA from two housekeeping genes, $\beta$-actin and $\beta$-2-microglobulin, were used to normalize gene expression and the product specificity was checked by melting curve analysis. Results were analyzed with the provided LightCycler ${ }^{\circledR} 480$ Software (version 1.5) (reference 04994884001, Roche). The $2-\Delta \Delta \mathrm{Ct} 2-\Delta \Delta \mathrm{Ct}$ comparative method for relative quantification was used to calculate differences in expression levels for each target gene among samples. The primers designed with the primer express programme were as follows (Forward: Fw; Reverse: Rv): murine actin- $\beta$ : Fw 5'-ACCAGTTCGCCATGGATGAC-3' and Rv 5'-CAATGGGGTACTTCAGGGTCAG-3'; murine Hmgcr Fw 5' -CGTAACCCAAAGGGTCA AGATG-3' Rv 5'-CAGACCCAAGGAAACCTTAGCC-3'; murine Ldlr: Fw 5'-AGTGTGATGGCCC CAACAAG-3' Rv 5'-CACTCGTTGGTCTTGCACTCC-3'; and murine Srebf2: Fw 5'-TCCTTCACTT AACCATGTGATCC-3’ Rv 5'-ATGGTAGGTCTCACCCAGGAG-3' . 


\subsection{Statistical Analysis}

Data are presented as the mean \pm SEM. Differences were evaluated by one-way ANOVA analysis, and were considered statistically significant when $p \leq 0.05$ (GraphPad Prism v.5 software, GraphPad Software, San Diego, CA, USA). Outliers identified by Grubbs' test were not considered for quantification (GraphPad Prism).

\section{Results}

\subsection{Body Weight, Food Intake and Lipid Metabolism Characterisation of WT and S-mice Fed a High-Fat,} High-Sucrose or Control Diet

Eight-week-old male and female WT and S-mice were fed with a HFHS or control diets for 16 weeks and were characterized. Control diet group was composed by 12 WT males, 13 WT females, 15 S-mouse males and $15 S$-mouse females. HFHS diet group was composed by 12 WT males, 13 WT females, 15 S-mouse males and $15 S$-mouse females. Over the months studied body weight increased with age, but transgenic mice showed lower body weight than WT mice (Figure 1, top panel, $p<0.01$ ). The HFHS diet increased the body weight in both genotypes and widened the difference between them.

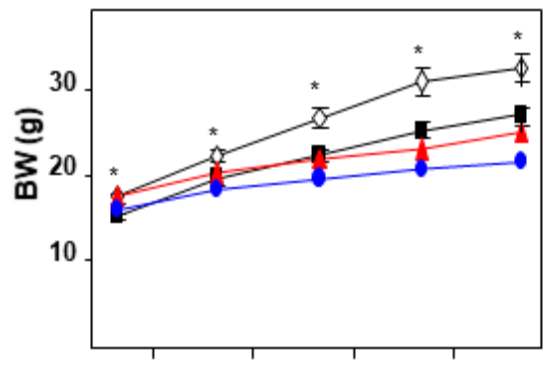

Start 1 month 2 month 3 month 4 month
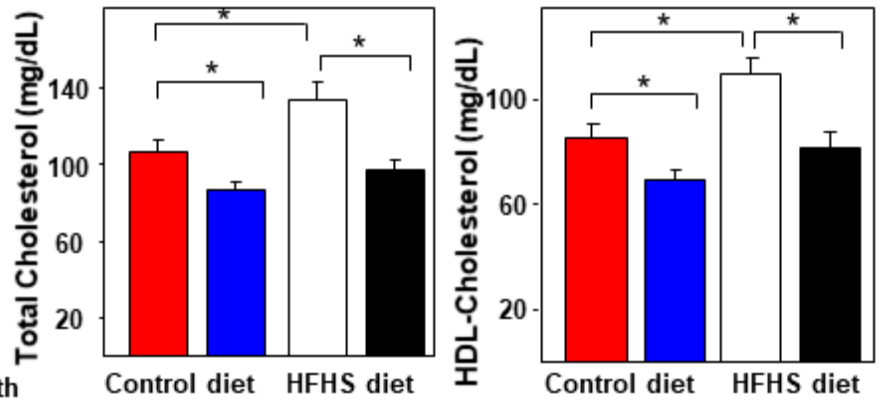
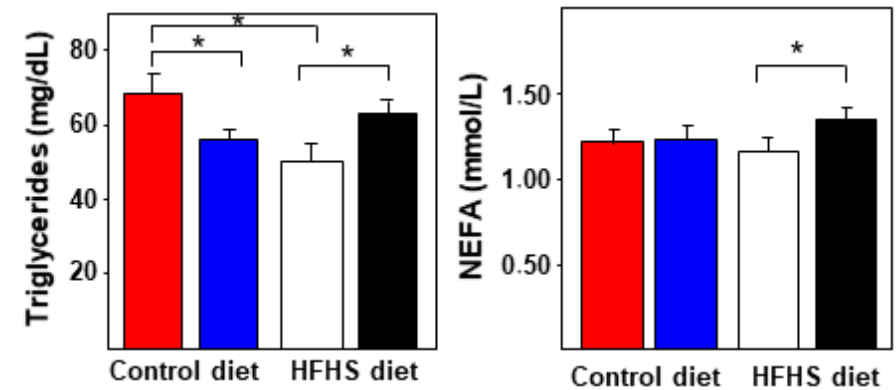

Control diet HFHS diet
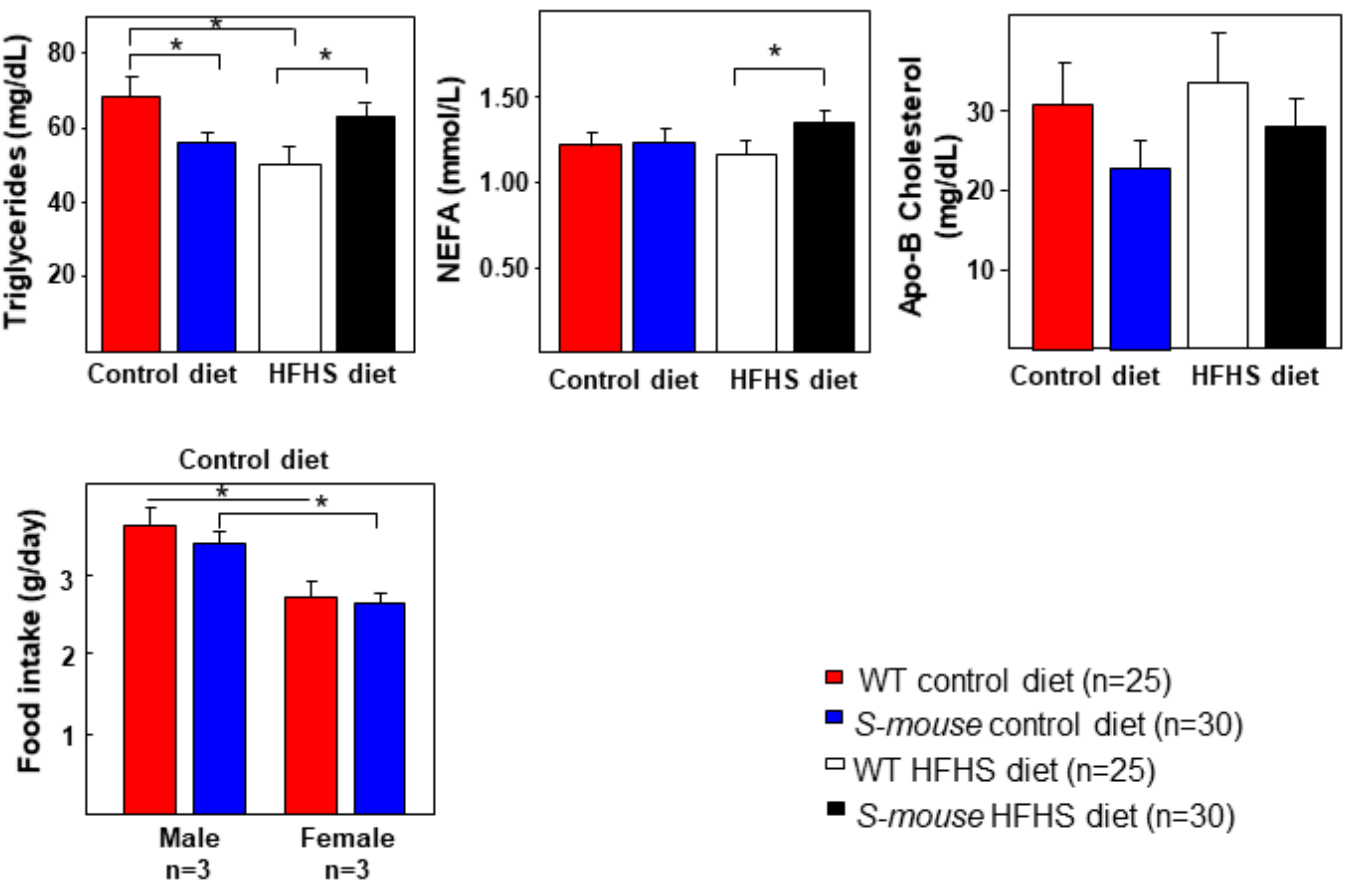

- WT control diet $(n=25)$

- S-mouse control diet $(n=30)$

$\square$ WT HFHS diet $(n=25)$

- S-mouse HFHS diet $(n=30)$

Figure 1. Plasmatic parameters in WT and S-mice fed a HFHS or control diet for 16 weeks. Evolution of body weight and total cholesterol, HDL-cholesterol, TG, NEFAs and apoB-cholesterol in fasted overnight levels in all mice groups. Data are presented as mean \pm SEM. Statistical analysis was performed using one-way ANOVA. * $p \leq 0.05$. HFHS high-fat, high-sucrose, BW body weight, NEFAS non-esterified fatty acid, HDL high-density lipoprotein, WT Wild type, TG triglycerides. 
Consistent with a role of SREBP-2 in lipid metabolism, lipid level analysis showed lower total cholesterol and HDL-cholesterol levels in S-mice fed a HFHS or control diet, although HFHS diet increased both total cholesterol and HDL-cholesterol in WT mice (Figure $1, p<0.01$ ). Triglycerides levels were lower in S-mice fed with control diet compared with WT mice but triglycerides were lower in S-mice under the control diet. HFHS diet increased triglycerides levels in S-mice while reducing triglycerides in WT mice. Finally, NEFAs is only higher in S-mice under HFHS diet when compared with WT mice (Figure 1, $p<0.05$ ). No changes were observed in apolipoprotein B (apoB)-cholesterol (Figure 1). To determine the underlying mechanisms behind the low BW observed in S-mice, we performed food intake analysis on control diet fed animals. Surprisingly, animals under control diet had the same feeding. We did not find any statistical differences between genotypes. The food intakes ranged from $2.5 \mathrm{~g} /$ day/mouse to $3.5 \mathrm{~g} /$ day/mouse. Feeding behavior in individually housed mice during the early stages of control diet feeding demonstrates that $S$-mice consume the same food than WT animals, it should be noted that the WT and S-mouse females showed a lower food intake compared with males with same genotype. We monitored food consumption over one week under ad libitum conditions. No difference in food intake was observed between transgenic and WT mice but differences between sexes was significant (Figure 1, lower panel, $p<0.05$ ). These differences in food intake between genders can have metabolic impact. In fact, if TG levels are separated by males and females under control diet (Supplementary Figure S3), there are differences in TG between WT males and WT females and they can be explained by this different food intake between males and females. However different food intake does not explain why TG levels in S-mice male and S-mice females under control diet are different.

\subsection{Carbohydrate Metabolism Characterisation of WT and S-mice Fed a High-Fat, High-Sucrose or Control Diet}

Carbohydrate metabolism analysis showed no changes in fasting basal glucose and insulin levels between genotypes under control diet but HFHS diet increased glucose levels over time (Figure 2A). As expected, fasting basal glucose in WT mice fed a HFHS diet was increased compared with levels in WT mice fed a control diet and S-mice (Figure 2A, $p<0.05$ ), and S-mice animals had higher levels on a HFHS diet than a control diet (Figure 2A, left panel, $p<0.05$ ). Basal glucose was higher in WT mice under HFHS diet than levels in S-mice. Insulin levels were higher in WT mice fed with HFHS diet compared with WT mice fed a control diet and S-mice under HFHS diet (Figure 2A, right panel, $p<0.05)$. In this way, the HFHS diet effect in WT animals and in S-mice showed increased HOMA-IR index compared with WT and S-mice fed with a control diet (Figure 2D, $p<0.05$ ). A trend was observed in the differences in HOMA-IR index between genotypes under HFHS diet (Figure 2D, $p<0.08$ ).

Glucose tolerance test (GTT), measured as the area under the curve (glucose curve vs. time, $\mathrm{AUC}_{\text {glucose }}$ ) (Figure $\left.2 \mathrm{~B}\right)$, showed no differences between genotypes in mice fed a HFHS or control diet, although at 15 min the S-mice under HFHS diet had lower levels of glucose than WT mice on the same diet $(p<0.015)$. In this way, in WT animals fed a HFHS diet showed increased glucose levels during GTT compared with $W T$ fed a control diet (Figure 2B, $p<0.05$ ). The glucose-stimulated insulin release during the test, expressed as $\mathrm{AUC}_{\text {insulin }}$ (insulin curve vs. time) (Figure $2 \mathrm{~B}, p<0.05$ ) showed lower levels in S-mice fed with either diet compared with WT mice.

These data indicate that $S$-mice required lower insulin release for the same glucose levels and curves, although, in insulin sensitivity analysis by insulin tolerance test (ITT) AUC glucose parameters showed no effect of Srebf2-overexpression in mice (Figure 2C). All these data may indicate that S-mice seem to be more protected against insulin resistance on a HFHS diet and overexpression of Srebf 2 . 


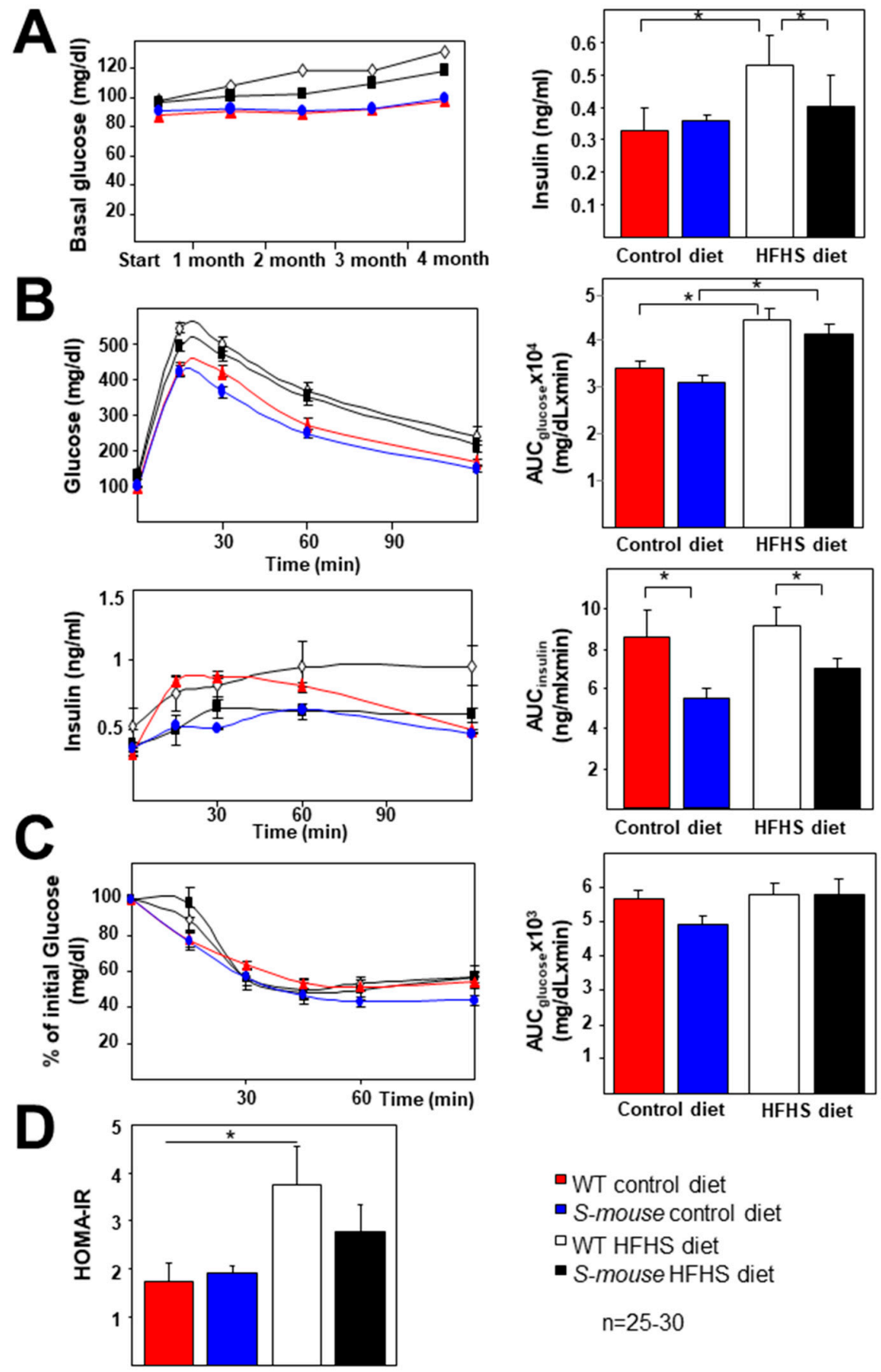

Figure 2. Glucose metabolism characterization under 16-week, high-fat, high-sucrose or control diet-fed WT and S-mice. (A) Evolution of fasting plasma glucose levels and insulin levels in all mice groups. (B) Plasmatic glucose levels during the GTT (top graph) and the area under the curve (AUC glucose $_{\text {) }}$ determined from the glucose measurements of the test (right panel) in all mice groups. Plasmatic glucose-stimulated insulin levels during the GTT (lower graph) and the $\mathrm{AUC}_{\text {insulin }}$ determined from the insulin measurements of the test (right panel). (C) Glucose levels (percentage relative to basal glucose levels) during ITT in $4 \mathrm{~h}$-fasted mice. Statistical analysis was performed using one-way ANOVA. (D) HOMA-IR index in four groups of mice. ${ }^{*} p \leq 0.05$. HFHS high-fat, high-sucrose, GTT glucose tolerance test, ITT insulin tolerance test, HOMA homeostasis model assessment.

\subsection{Increased Dosage of Srebf2 Showed Low Pancreatic $\beta$-Cell Numbers in S-mice Fed a High-Fat,} High-Sucrose and Control Diet

To explore the causes of the differences in glucose-stimulated insulin secretion between WT and S-mice, pancreatic characterization was then performed. Analysis of pancreatic islets by insulin 
immunohistochemistry of cross-sections showed the relative area occupied by $\beta$-cells was significantly decreased in S-mice fed 16 weeks HFHS and control diet compared with their respective controls (Figure 3A, $p<0.05$ ). The diet effect showed that Srebf2-overexpression in S-mice under HFHS diet increased $\beta$-cell levels compared to $S$-mice fed a control diet. Similarly, WT mice showed increased $\beta$-cell levels when fed HFHS diet as opposed to a control diet (Figure $3 \mathrm{~A}, p<0.05$ ). Therefore, the HFHS diet produced an increase in $\beta$-cell levels in both animals, but the $\beta$-cell numbers were lower in $S$-mice $(p<0.05)$. No significant differences were observed in the islet number between the four groups of mice (Figure 3B).

A

B
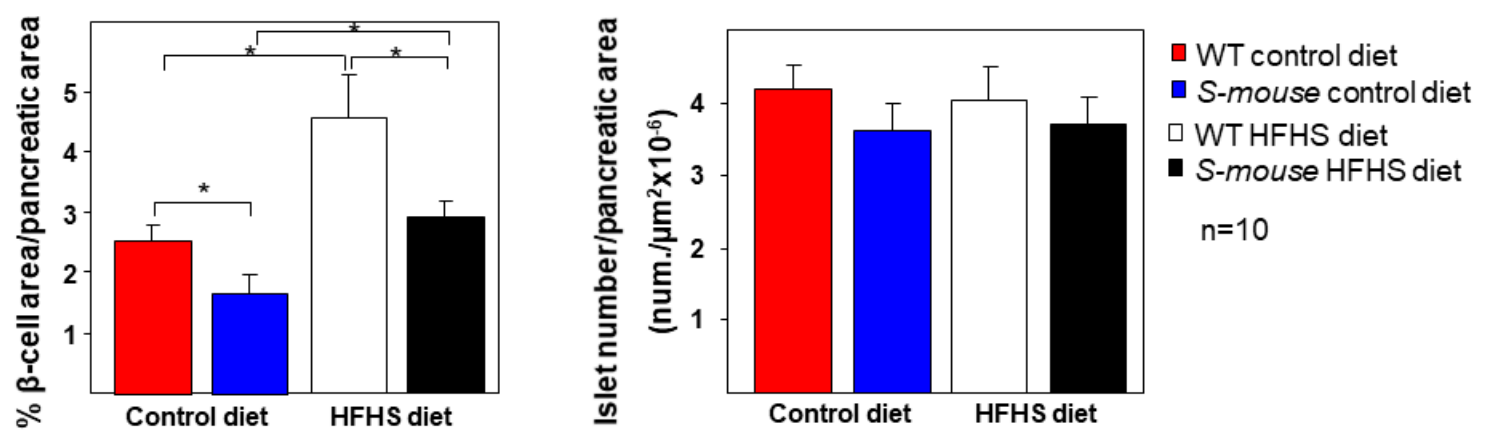

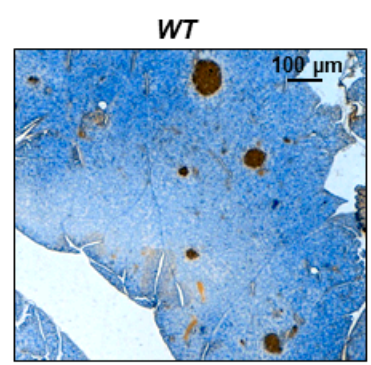

CONTROL DIET

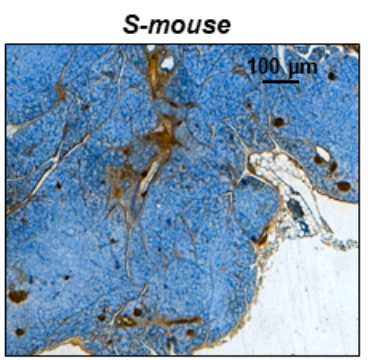

CONTROL DIET

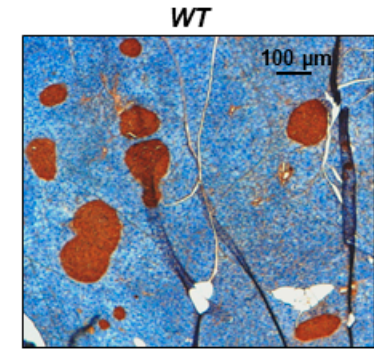

HFHS DIET

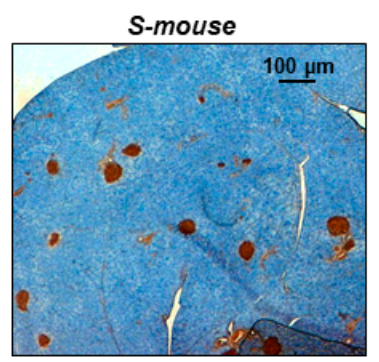

HFHS DIET

Figure 3. Pancreatic islet characterisation in WT and S-mice fed high-fat, high-sucrose or control diet for 16 weeks. (A) Quantification of $\beta$-cell area (in percentage relative to pancreatic area) and (B) relative islet number in the pancreas of all groups of mice identified by anti-insulin immunohistochemistry. Representative images of the immunohistochemistry are shown. Data are presented as mean \pm SEM. Statistical analysis was performed using one-way ANOVA. ${ }^{*} p \leq 0.05$. HFHS high-fat, high-sucrose.

These results indicate that the differences in insulin secretion were due to differences in $\beta$-cell mass and not to the number of islets.

\subsection{S-mice Fed a High-Fat, High-Sucrose Diet Have Increased Hepatic Triglyceride Content Compared with S-mice Fed Control Diet}

Bearing in mind the relationship between non-alcoholic fatty liver disease (NAFLD), dyslipidemia, glucose metabolism derangement and blood triglycerides levels, hepatic analysis was performed. The result showed no differences between genotypes in hepatic triglyceride content, indicating that Srebf2-overexpression has no effect on fatty liver disease in mice fed with HFHS or control diet. However, the diet effect showed increased hepatic triglyceride content in mice fed a HFHS diet compared with mice fed a control diet (Figure 4). These results indicate that Srebf2-overexpression does not play a relevant role in increasing fatty liver disease in mice fed with a HFHS diet. 

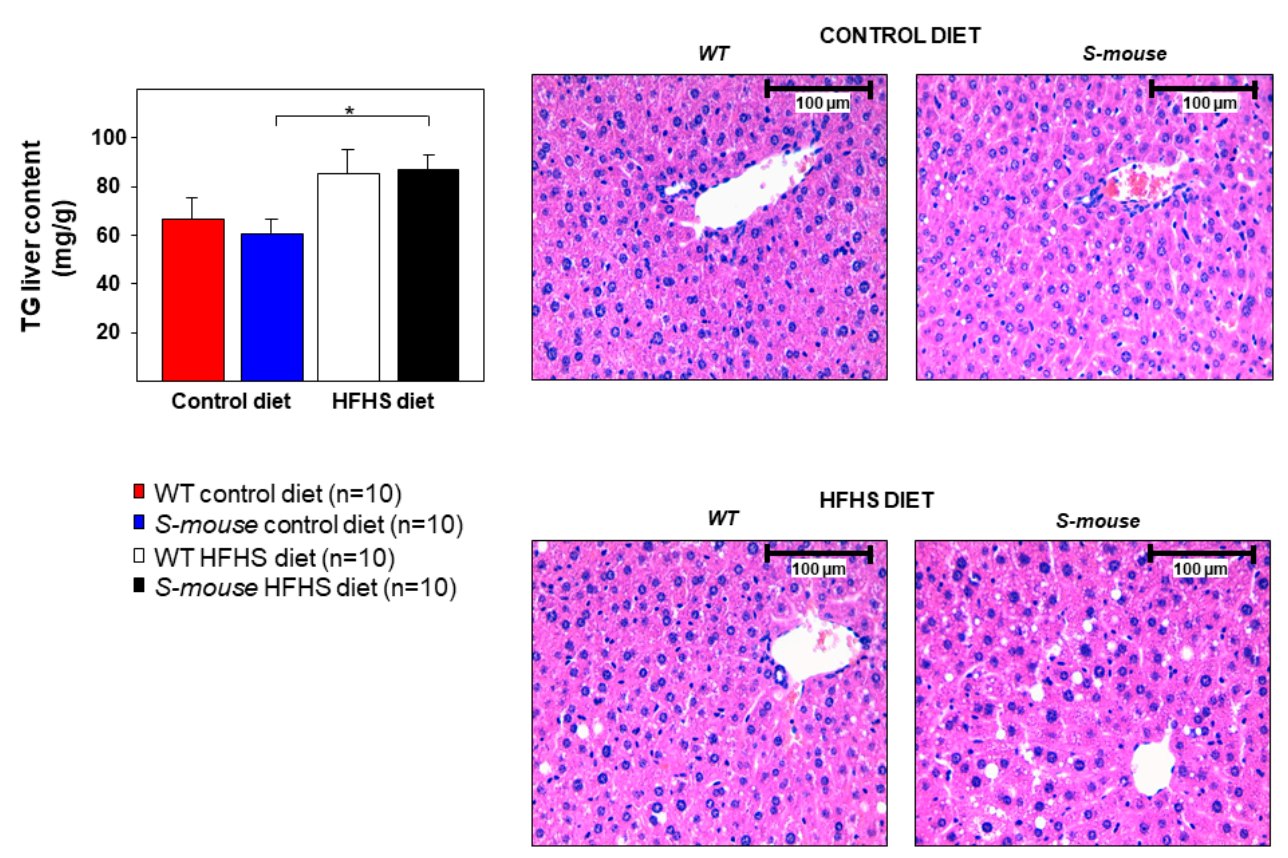

Figure 4. Liver characterisation in WT and S-mice fed high-fat, high-sucrose or control diet for 16 weeks. Analysis of triglyceride content in liver in all mice groups. Images of hematoxylin-eosin stained sections showing lipid droplets (20× magnification). Data are presented as mean \pm SEM. Statistical analysis was performed using one-way ANOVA. * $p \leq 0.05$. HFHS high-fat, high-sucrose, TG triglyceride.

\subsection{Adipose Tissue Characterization in WT and S-mice Fed a High-Fat, High-Sucrose or Control Diet}

Given the observed differences in body weight between different genotypes and the possible diet effect, adipose tissue was next analyzed. Adipocytes were characterized by haematoxylin-eosin stains in abdominal cross-sectional fat. These studies showed no differences in mice fed a control diet, although in S-mice tended to be smaller. Adipocyte size increased in WT and S-mice under a HFHS diet, although the increase in WT mice was much greater than in transgenic mice (Figure 5A, $p<0.01$ ). Adipocyte number analysis showed reduced numbers in WT mice under HFHS diet when compared with WT mice under control diet and or S-mice under HFHS diet (Figure $5 \mathrm{~B}, p<0.01$ ), probably due to their larger size. No differences were observed in mice fed a control diet (Figure 5B). Distribution diagram of adipocyte sizes in different diets and mouse genotypes can be watch in Supplementary Figure S4. These results indicate that $S$-mice have significant alterations in adipocytes metabolism or regulation, involving reduced capacity for body weight gain.

\subsection{Increased Activation of Srebf2, Ldlr and Hmgcr in S-mice}

To verify Srebf2 overexpression and to understand these metabolic alterations and gene expression regulation by Srebf 2 we analyzed the mRNA levels of Srebf2 and two genes regulated by Srebf2 ( $L d l r$ and Hmgcr). We found increased mRNA levels of Srebf2, Ldlr and Hmgcr in S-mice. These mice fed with HFHS showed increased Srebf2 and Hmgcr mRNA levels (Figure 6, left panels, $p<0.05$ ). In the same way, S-mice fed a control diet showed higher Srebf2 levels than WT mice fed a control diet (Figure 6, left panel, $p<0.05)$. HFHS diet increased Srebf2 mRNA levels in S-mice compared with mRNA levels in S-mice fed a control diet (Figure 6, left panel, $p<0.05$ ). Similarly, analysis revealed that $L d l r$ mRNA levels were also higher in S-mice under both diets (Figure 6, right panel, $p<0.05$ ) than in WT animals. Lastly, Hmgcr mRNA expression was significantly higher in S-mice fed a HFHS diet compared with those of WT mice fed a HFHS diet (Figure 6, low panel, $p<0.05$ ). In the same way, S-mice under control diet showed enhanced Hmgcr levels compared with those for WT mice fed a control diet (Figure 6, low panel, $p=0.05$ ). These results indicate that Srebf2 overexpression increases the mRNA levels of Srebf2, Ldlr and Hmgcr in livers of S-mice fed with a HFHS and control diet and that Srebf2 overexpression most likely increase the mRNA levels of other genes regulated by the SREBP-2 system. 
A

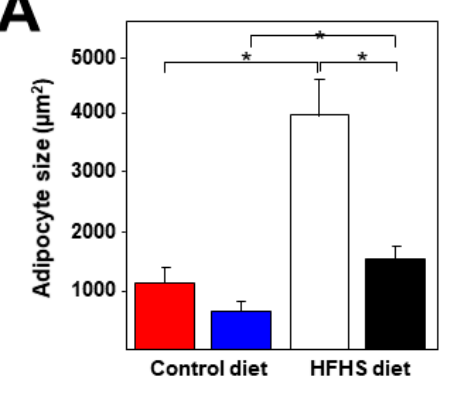

B

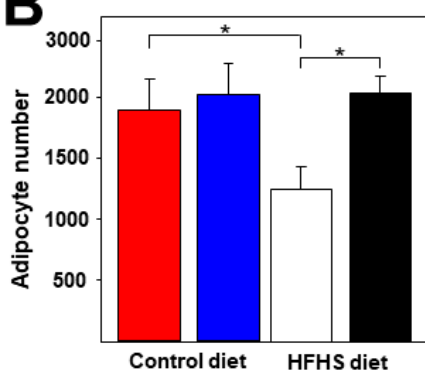

WT control diet $(n=10)$

- S-mouse control diet $(n=10)$

$\square$ WT HFHS diet $(n=10)$

- S-mouse HFHS diet $(n=10)$

\section{C}
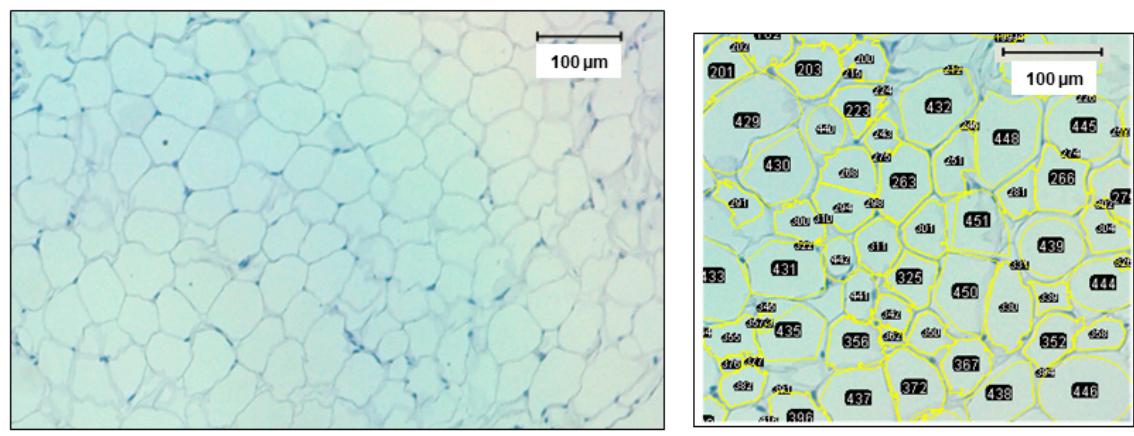

Figure 5. Adipose tissue characterization in WT and S-mice fed high-fat, high-sucrose or control diet for 16 weeks. (A) Quantification of adipocyte size and (B) adipocyte number in the adipose tissue for all groups of mice identified by hematoxylin-eosin staining. (C) Representative image quantified in A $\& B$ is shown. The ImageJ data acquisition detects the shape of the adipocyte and counts the number in the image. The same program shows the area of each adipocyte. Data are presented as mean \pm SEM. Statistical analysis was performed using one-way ANOVA. ${ }^{*} p \leq 0.05$. HFHS high-fat, high-sucrose.
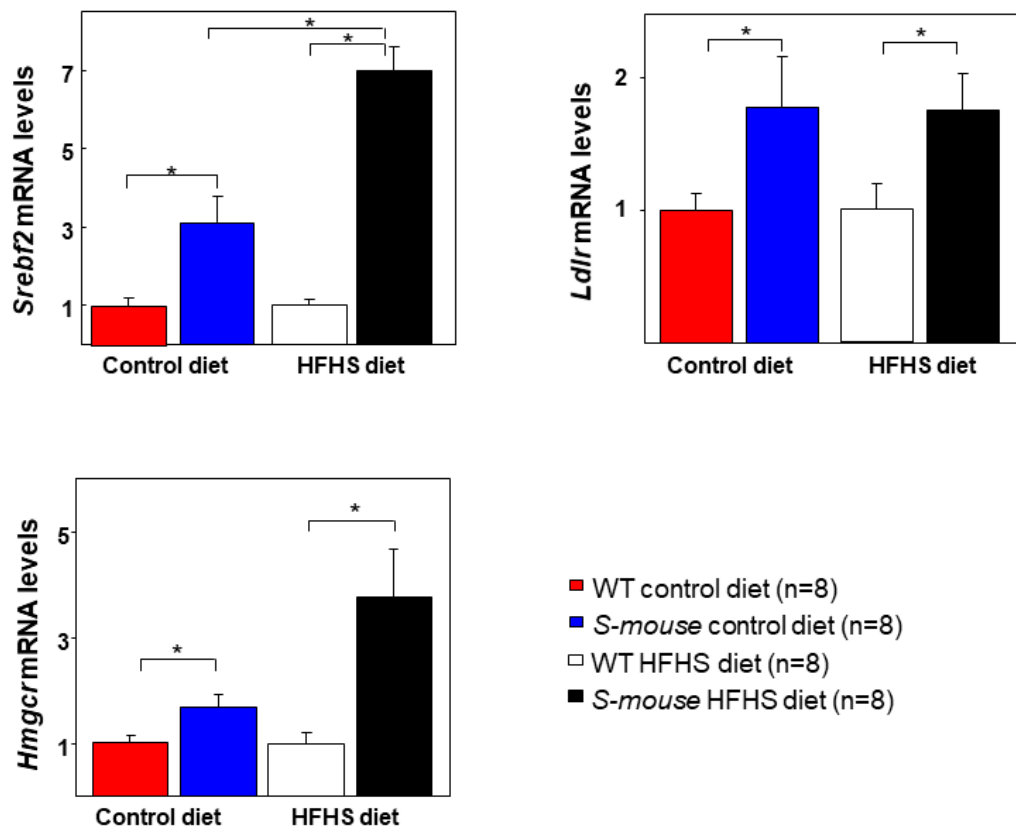

- WT control diet $(\mathrm{n}=8)$

- S-mouse control diet $(n=8)$

$\square$ WT HFHS $\operatorname{diet}(n=8)$

- S-mouse HFHS diet $(n=8)$

Figure 6. Expression analysis in liver in WT and S-mice fed high-fat, high-sucrose or control diet for 16 weeks. Srebf2, Ldlr and Hmgcr hepatic mRNA levels were normalized to actin-ßexpression. Relative expression shown was calculated using the $2^{-(\Delta \Delta C t)}$ method. Statistical analysis was performed using one-way ANOVA. ${ }^{*} p \leq 0.05$. HFHS high-fat, high-sucrose, Srebf2 Sterol regulatory element-binding transcription factor 2, Ldlr Low-density lipoprotein receptor, Hmgcr 3-Hydroxy-3-methylglutaryl-CoA reductase. 


\section{Discussion}

To understand the role of Srebf2 in metabolism we generated S-mice which include extra copies of Srebf 2 mouse gene in upstream and downstream regions (approx. 10,000 bp and $5000 \mathrm{bp}$, respectively). The following differences between S-mice and other Srebf2 transgenic mice were found: moderate overexpression of Srebf2 gene regulated by its own promoter, expression in normal tissues and under own gene regulation, production of complete SREBP-2 protein (regulated by normal SREBP system) and the presence of miR-33a in the genetic sequence used. These mice can provide important information about different metabolic alterations related to body mass index (BMI), glucose and lipid metabolism and how they are regulated.

Although previous transgenic constructions had very high expression in one or two tissues of the active form of SREBP-2 (including NH2 acidic transactivation domain and bHLH-Zip DNA binding domain), they lack the $\mathrm{COOH}$-terminal regulatory domain which produces constitutively active SREBP-2 [28-31]. These modifications result in absence of SREBP-2 regulation at transcriptional and posttranscriptional levels. Finally, most constructs are based on cDNA, therefore they lack miR-33A. This miRNA is encoded by intron 16 of Srebf2 gene in mice and SREBF2 gene in humans, with important roles in gene metabolism regulation modulating SREBP-2 activity [18,32,33]. Expression levels of mirR33a are correlated to the levels of Srebf2 gene expression in some cell types [19,32-34]. Studies have shown that Srebf2 activation increases cholesterol levels in blood, tissues and cells [28,29,31]. Overexpression of Srebf2 increases lipotoxicity in different kind of cells, including PBCs and hepatocytes, inducing DM and non-alcoholic steatohepatitis [29,35-37]. Moreover, very high overactivity of active SREBP-2 peptide in PBCs induces low weight, lower PBC mass, death and impaired insulin secretion in mice, which develop severe diabetes [29]. SREBP-2 overactivity in liver increases body weight, cholesterol and triglyceride synthesis levels and inhibits IRS expression in mice [28,38]. In rats, SREBP-2 overactivity in liver produces similar effects as in mice: reduced serum insulin levels and increased glucose levels [30]. Another study shows that mice with one Srebf2 copy have reduced levels of glucose, postprandial reduced levels of insulin, reduced weight and triglycerides [39]. To our knowledge, although studies describe a notable point mutation affecting SREBP-2 functionality in mice, there is no data about glucose metabolism in these mice [40].

We demonstrated that an extra copy of Srebf2 gene that can produce overexpression in cells where it is usually expressed has a significant effect on BW, T2DM and LMD parameters. Under a control diet, S-mice showed reduced BW, insulin secretion in GTT, and reduced levels of total and HDL cholesterol and TG. The HFHS diet produced or increased differences with WT mice in BW, total and HDL cholesterol and basal insulin and HOMA. This diet increased triglycerides and NEFAs plasmatic levels in S-mice compared to WT mice (Figure 1, Figure 2, Figure 3). Under HFHS diet S-mice gained body weight, but proportionally less than WT mice. Body weight increased by about $27 \%$ in $S$-mice while in WT the increase was about $32 \%$ (Figure $1, p<0.001$ ). These data are consistent with those found in mice overexpressing active SREBP-2 in PBCs caused low BW [29] and others [28] that found similar weight changes in male mice overexpressing active SREBP-2 in liver and fat. In this way, adipocyte size increased in both animals with a HFHS diet but in S-mice the increase is about $250 \%$ while in $W T$ it is about $370 \%$ (Figure $5, p<0.01$ ). These results concur with reduced adipogenic activity showed in SREBP-2 transgenic SHR rats, although these rats had increased BW [30]. One of the mechanisms involved in adipocyte size can be the increased cholesterol levels in these cells due to Srebf-2 overexpression which can limit their size [41]. The food intake experiment over a 7-days period was not altered in S-mice. No differences were found in short-term food intake between WT and transgenic mice but males showed more feeding than females (Figure $1, p<0.05$ ). Our study confirmed that overexpression of SREBP-2 in mice does not affect food intake. The study showed that eight-week-old S-mice on a control diet did not increase food intake, and further assessment of feeding behavior confirmed that S-mice maintained level of food intake than WT animals when fed the same diet. Our data suggest that the increment in food intake is not the primary factor for the obesity phenotype in WT mice. While this difference in food intake is the same, it does not appear to be 
enough to drive the weight gain and metabolic dysfunction. The weight gain could be correlated with the effect of the overexpression of SREBP-2 and with an increase of energy deposits in fat, decrease in voluntary activity, a drop in energy expenditure [42,43].

In both mice types a HFHS diet induced higher basal glucose levels and glucose intolerance compared with control diet. After 16 weeks on the HFHS diet, the S-mice had lower glucose and insulin levels than WT mice. The HOMA index showed no differences between genotypes, but under the HFHS diet HOMA-IR increased in all animals and tended to be high in WT animals compared with S-mice (Figure 2D). These data may indicate that moderate Srebf-2 overexpression allows improved glucose metabolism. The number of pancreatic islets is similar in all animals, indicating that moderate Srebf-2 overexpression allows their development, in contrast with mice with very high expression of active SREBP-2 in PBCs [29]. PBC mass is lower in S-mice than WT mice under control and HFHS diets. These facts could explain reduced insulin secretion and plasma levels in S-mice and indicate that $S$-mice require lower insulin levels and do not expand pancreatic islets to the same degree as $W T$, as happens in other mice or depending on diets [44-47].

Analysis of mRNA levels in the liver of Srebf2, $\mathrm{Ldlr}$ and $\mathrm{Hmgcr}$ (the last two regulated by SREBP-2 and involved in cholesterol uptake and synthesis) revealed increased levels in S-mice and a notable rise under HFHS diet in Srebp2 and Hmgcr, while there was no change in Ldlr with a HFHS diet. Induced LDLR overexpression by Srebf2 might explain the reduced total cholesterol blood levels in both diets.

We found marked differences between $S$-mice and other transgenic animals in many parameters connected with metabolic alterations and the role of SREBP-2 in them. Most of these changes are increased by HFHS diet. The effects can be partly due to transcriptional and posttranscriptional regulation, but could also owe to metabolic regulation by miR-33a, not analyzed in the current work, as could HDL levels [31,32]. All these data indicate a relevant effect of Srebf2 overexpression on hepatocytes, adipocytes and PBCs, which is increased by HFHS diet. In general, Srebp-2 overexpression seems to have beneficial effects on all the measured metabolic parameters except HDL levels. SREBP-2 is an interesting pharmacological target for treating different diseases including DM, metabolic syndrome, dyslipidaemia and cancer [48-50]. Our results pave the way for future research on the organ-specific action and mechanisms involved in SREBP-2 to facilitate its use as a drug target.

In summary, the present study demonstrates that a moderate Srebf2-overexpression produces reduced weight and modulates lipid and glucose metabolism compared with WT mice. In addition, a HFHS diet increases these differences, suggesting a role for Srebf2 in diet induced effects in relation to these metabolic alterations. In general, complete Srebf2 gene overexpression improves metabolic parameters related to cardiovascular risk and further studies are justified to assess the viability of therapeutic strategies based around modulation of SREBP-2 and miR-33a.

Supplementary Materials: The following are available online at http://www.mdpi.com/2072-6643/12/10/3130/s1, Figure S1: SREBP activation, Figure S2: Transfection vector, Figure S3: Plasma TG levels in male and female mice, Figure S4: Adipocyte size distribution, Table S1: Diets composition.

Author Contributions: Conceptualization, I.A.-B., H.G.-N., S.M.-H., J.T.R., A.F.-I., F.J.C. and A.-B.G.-G.; methodology, I.A.-B., Á.V., H.G.-N., S.B., A.F.-I., J.C., S.M.-H., J.T.R. and A.-B.G.-G.; formal analysis, I.A.-B., Á.V., H.G.-N., S.B., J.C., F.J.C., A.-B.G.-G.; investigation, I.A.-B., Á.V., H.G.-N., S.B., J.T.R., S.M.-H., J.C., F.J.C. and A.-B.G.-G.; resources, S.M.-H., J.T.R., A.F.-I., J.C.; data curation, I.A.-B., A.-B.G.-G.; writing-original draft preparation, I.A.-B., F.J.C., A.-B.G.-G.; writing-review and editing, I.A.-B., S.B., Á.V., H.G.-N., J.T.R., S.M.-H., J.C., A.F.-I., F.J.C., A.-B.G.-G.; visualization, I.A.-B., F.J.C., A.-B.G.-G.; supervision, J.C., H.G.-N., A.F.-I., F.J.C., A.-B.G.-G.; project administration, F.J.C., A.-B.G.-G.; funding acquisition, F.J.C. All authors have read and agreed to the published version of the manuscript.

Funding: This study was supported by CIBERDEM (Diabetes and Associated Metabolic Diseases), a Carlos III Health Institute, Spanish Health Ministry initiative, and research grants PI14/00874, PI17/00544 from the Fondo de Investigaciones Sanitarias, Spain.

Acknowledgments: The author would like to thank Ana Díaz for her help with animal care. Sergio Martinez-Hervas is an investigator in the 'Juan Rodes' program (JR18/00051) financed by the Instituto de Salud Carlos III and the European Regional Development Fund (FEDER). Irene Andres-Blasco is a researcher under a APOSTD-2019 grant (European Social Fund, Conselleria de Innovacion, Universidades, Ciencia y Sociedad Digital de la Generalitat Valenciana). 
Conflicts of Interest: The authors declare no conflict of interest. The funders had no role in the design of the study; in the collection, analyses, or interpretation of data; in the writing of the manuscript, or in the decision to publish the results.

\section{References}

1. Nunn, A.V.; Bell, J.D.; Guy, G.W. Lifestyle-induced metabolic inflexibility and accelerated ageing syndrome: Insulin resistance, friend or foe? Nutr. Metab. 2009, 6, 16. [CrossRef] [PubMed]

2. Zambon, S.; Zanoni, S.; Romanato, G.; Corti, C.M.; Noale, M.; Sartori, L.; Musacchio, E.; Baggio, G.; Crepaldi, G.; Manzato, E. Metabolic Syndrome and All-Cause and Cardiovascular Mortality in an Italian Elderly Population. Diabetes Care 2009, 32, 153-159. [CrossRef] [PubMed]

3. Buettner, R.; Scholmerich, J.; Bollheimer, L.C. High-fat diets: Modeling the metabolic disorders of human obesity in rodents. Obesity 2007, 15, 798-808. [CrossRef] [PubMed]

4. Ellacott, K.L.; Morton, G.J.; Woods, S.C.; Tso, P.; Schwartz, M.W. Assessment of feeding behavior in laboratory mice. Cell Metab. 2011, 12, 10-17. [CrossRef]

5. Sumiyoshi, M.; Sakanaka, M.; Kimura, Y. Chronic intake of high-fat and high-sucrose diets differentially affects glucose intolerance in mice. J. Nutr. 2006, 136, 582-587. [CrossRef]

6. Shimano, H.; Sato, R. SREBP-regulated lipid metabolism: Convergent physiology—Divergent pathophysiology. Nat. Rev. Endocrinol. 2017, 13, 710-730. [CrossRef]

7. Osborne, T.; Espenshade, P.J. Evolutionary conservation and adaptation in the mechanism that regulates SREBP action: What a long, strange tRIP it's been. Genes Dev. 2009, 23, 2578-2591. [CrossRef]

8. Bengoechea-Alonso, M.T.; Ericsson, J. SREBP in signal transduction: Cholesterol metabolism and beyond. Curr. Opin. Cell Biol. 2007, 19, 215-222. [CrossRef]

9. Durst, R.; Jansen, A.; Erez, G.; Bravdo, R.; Butbul, E.; Avi, L.B.; Shpitzen, S.; Lotan, C.; Leitersdorf, E.; Defesche, J.; et al. The discrete and combined effect of SREBP-2 and SCAP isoforms in the control of plasma lipids among familial hypercholesterolaemia patients. Atherosclerosis 2006, 189, 443-450. [CrossRef]

10. Liu, F.-H.; Song, J.-Y.; Meng, X.-R.; Ma, J.; Wang, H.-J. The gene-gene interaction of INSIG-SCAP-SREBP pathway on the risk of obesity in Chinese children. BioMed Res. Int. 2014, 2014, 538564. [CrossRef]

11. Shao, W.; Espenshade, P.J. Expanding roles for SREBP in metabolism. Cell Metab. 2012, 16, 414-419. [CrossRef] [PubMed]

12. Shimomura, I.; Bashmakov, Y.; Horton, J.D. Increased levels of nuclear SREBP-1c associated with fatty livers in two mouse models of diabetes mellitus. J. Biol. Chem. 1999, 274, 30028-30032. [CrossRef] [PubMed]

13. Yabe, D.; Xia, Z.-P.; Adams, C.M.; Rawson, R.B. Three mutations in sterol-sensing domain of SCAP block interaction with insig and render SREBP cleavage insensitive to sterols. Proc. Natl. Acad. Sci. USA 2002, 99, 16672-16677. [CrossRef] [PubMed]

14. Yang, Y.; Song, J.Y.; Wang, S.; Liu, F.H.; Zhang, Y.N.; Shang, X.R.; Wang, H.J.; Ma, J. Genetic variations in sterol regulatory element binding protein cleavage-activating protein (SCAP) are associated with blood pressure in overweight/obese Chinese children. PLoS ONE 2017, 12, e0177973. [CrossRef] [PubMed]

15. Vergnes, L.; Chin, R.G.; de Aguiar Vallim, T.; Fong, L.G.; Osborne, T.F.; Young, S.G.; Reue, K. SREBP-2-deficient and hypomorphic mice reveal roles for SREBP-2 in embryonic development and SREBP-1c expression. J. Lipid Res. 2016, 57, 410-421. [CrossRef]

16. Muller, P.; Miserez, A.R. Identification of mutations in the gene encoding sterol regulatory element binding protein (SREBP)-2 in hypercholesterolaemic subjects. J. Med. Genet. 2002, 39, 271-275. [CrossRef] [PubMed]

17. Musso, G.; Cassader, M.; Bo, S.; De Michieli, F.; Gambino, R. Sterol regulatory element-binding factor 2 (SREBF-2) predicts 7-year NAFLD incidence and severity of liver disease and lipoprotein and glucose dysmetabolism. Diabetes 2013, 62, 1109-1120. [CrossRef]

18. Davalos, A.; Goedeke, L.; Smibert, P.; Ramirez, C.M.; Warrier, N.P.; Andreo, U.; Cirera-Salinas, D.; Rayner, K.; Suresh, U.; Pastor-Pareja, J.C.; et al. miR-33a/b contribute to the regulation of fatty acid metabolism and insulin signaling. Proc. Natl. Acad. Sci. USA 2011, 108, 9232-9237. [CrossRef]

19. Najafi-Shoushtari, S.H.; Kristo, F.; Li, Y.; Shioda, T.; Cohen, D.E.; Gerszten, R.E.; Näär, A.M. MicroRNA-33 and the SREBP host genes cooperate to control cholesterol homeostasis. Science 2010, 328, 1566-1569. [CrossRef]

20. Ramírez, C.M.; Goedeke, L.; Rotllan, N.; Yoon, J.-H.; Cirera-Salinas, D.; Mattison, J.A.; Suárez, Y.; de Cabo, R.; Gorospe, M.; Fernández-Hernando, C. MicroRNA 33 regulates glucose metabolism. Mol. Cell. Biol. 2013, 33, 2891-2902. [CrossRef] 
21. Wijesekara, N.; Zhang, L.-h.; Kang, M.H.; Abraham, T.; Bhattacharjee, A.; Warnock, G.L.; Verchere, C.B.; Hayden, M.R. miR-33a modulates ABCA1 expression, cholesterol accumulation, and insulin secretion in pancreatic islets. Diabetes 2012, 61, 653-658. [CrossRef] [PubMed]

22. Blesa, S.; Olivares, M.D.; Alic, A.S.; Serrano, A.; Lendinez, V.; González-Albert, V.; Olivares, L.; Martínez-Hervás, S.; Juanes, J.M.; Marín, P.; et al. Easy One-Step Amplification and Labeling Procedure for Copy Number Variation Detection. Clin. Chem. 2020, 66, 463-473. [CrossRef] [PubMed]

23. Gonzalez-Navarro, H.; Nabah, Y.N.A.; Vinue, A.; Andres-Manzano, M.J.; Collado, M.; Serrano, M.; Andres, V. p19(ARF) deficiency reduces macrophage and vascular smooth muscle cell apoptosis and aggravates atherosclerosis. J. Am. Coll. Cardiol. 2010, 55, 2258-2268. [CrossRef] [PubMed]

24. Gonzalez-Navarro, H.; Vila-Caballer, M.; Pastor, M.F.; Vinue, A.; White, M.F.; Burks, D.; Andres, V. Plasma insulin levels predict the development of atherosclerosis when IRS2 deficiency is combined with severe hypercholesterolemia in apolipoprotein E-null mice. Front. Biosci. 2007, 12, 2291-2298. [CrossRef]

25. Gonzalez-Navarro, H.; Vinue, A.; Vila-Caballer, M.; Fortuno, A.; Beloqui, O.; Zalba, G.; Burks, D.; Diez, J.; Andres, V. Molecular mechanisms of atherosclerosis in metabolic syndrome: Role of reduced IRS2-dependent signaling. Arterioscler. Thromb. Vasc. Biol. 2008, 28, 2187-2194. [CrossRef]

26. Norris, A.W.; Chen, L.; Fisher, S.J.; Szanto, I.; Ristow, M.; Jozsi, A.C.; Hirshman, M.F.; Rosen, E.D.; Goodyear, L.J.; Gonzalez, F.J.; et al. Muscle-specific PPARgamma-deficient mice develop increased adiposity and insulin resistance but respond to thiazolidinediones. J. Clin. Investig. 2003, 112, 608-618. [CrossRef]

27. Osman, S.O.; Selway, J.L.; Kepczyńska, M.A.; Stocker, C.J.; O’Dowd, J.F.; Cawthorne, M.A.; Arch, J.R.S.; Jassim, S.; Langlands, K. A novel automated image analysis method for accurate adipocyte quantification. Adipocyte 2013, 2, 160-164. [CrossRef]

28. Horton, J.D.; Shimomura, I.; Brown, M.S.; Hammer, R.E.; Goldstein, J.L.; Shimano, H. Activation of cholesterol synthesis in preference to fatty acid synthesis in liver and adipose tissue of transgenic mice overproducing sterol regulatory element-binding protein-2. J. Clin. Investig. 1998, 101, 2331-2339. [CrossRef]

29. Ishikawa, M.; Iwasaki, Y.; Yatoh, S.; Kato, T.; Kumadaki, S.; Inoue, N.; Yamamoto, T.; Matsuzaka, T.; Nakagawa, Y.; Yahagi, N.; et al. Cholesterol accumulation and diabetes in pancreatic beta-cell-specific SREBP-2 transgenic mice: A new model for lipotoxicity. J. Lipid Res. 2008, 49, 2524-2534. [CrossRef]

30. Landa, V.; Zidek, V.; Mlejnek, P.; Simakova, M.; Silhavy, J.; Trnovska, J.; Kazdova, L.; Pravenec, M. Sterol regulatory element binding protein 2 overexpression is associated with reduced adipogenesis and ectopic fat accumulation in transgenic spontaneously hypertensive rats. Physiol. Res. 2014, 63, 587-590.

31. Ma, K.; Malhotra, P.; Soni, V.; Hedroug, O.; Annaba, F.; Dudeja, A.; Shen, L.; Turner, J.R.; Khramtsova, E.A.; Saksena, S.; et al. Overactivation of intestinal SREBP2 in mice increases serum cholesterol. PLoS ONE 2014, 9 , e84221. [CrossRef] [PubMed]

32. Gerin, I.; Clerbaux, L.A.; Haumont, O.; Lanthier, N.; Das, A.K.; Burant, C.F.; Leclercq, I.A.; MacDougald, O.A.; Bommer, G.T. Expression of miR-33 from an SREBP2 intron inhibits cholesterol export and fatty acid oxidation. J. Biol. Chem. 2010, 285, 33652-33661. [CrossRef] [PubMed]

33. Horie, T.; Ono, K.; Nishi, H.; Horiguchi, M.; Nakamura, T.; Nagao, K.; Kinoshita, M.; Kuwabara, Y.; Marusawa, H.; Iwanaga, Y.; et al. MicroRNA-33 encoded by an intron of sterol regulatory element-binding protein 2 (Srebp2) regulates HDL in vivo. Proc. Natl. Acad. Sci. USA 2010, 107, 17321-17326. [CrossRef] [PubMed]

34. Marquart, T.J.; Allen, R.M.; Ory, D.S.; Baldan, A. miR-33 links SREBP-2 induction to repression of sterol transporters. Proc. Natl. Acad. Sci. USA 2010, 107, 12228-12232. [CrossRef] [PubMed]

35. Brunham, L.R.; Kruit, J.K.; Verchere, C.B.; Hayden, M.R. Cholesterol in islet dysfunction and type 2 diabetes. J. Clin. Investig. 2008, 118, 403-408. [CrossRef]

36. Hao, M.; Head, W.S.; Gunawardana, S.C.; Hasty, A.H.; Piston, D.W. Direct effect of cholesterol on insulin secretion: A novel mechanism for pancreatic beta-cell dysfunction. Diabetes 2007, 56, 2328-2338. [CrossRef]

37. Malhotra, A.A.; Aloman, C.; Khadra, H.; Ooka, K.; Gill, R.K.; Saksena, S.; Dudeja, P.K.; Alrefai, W.A. Overactivation of intestinal sterol response element-binding protein 2 promotes diet-induced nonalcoholic steatohepatitis. Am. J. Physiol. Gastrointest. Liver Physiol. 2017, 313, G376-G385. [CrossRef]

38. Ide, S.H.; Yahagi, N.; Matsuzaka, T.; Nakakuki, M.; Yamamoto, T.; Nakagawa, Y.; Takahashi, A.; Suzuki, H.; Sone, H.; Toyoshima, H.; et al. SREBPs suppress IRS-2-mediated insulin signalling in the liver. Nat. Cell Biol. 2004, 6, 351-357. [CrossRef] 
39. Rong, S.; Cortés, V.A.; Rashid, S.; Anderson, N.N.; McDonald, J.G.; Liang, G.; Moon, Y.A.; Hammer, R.E.; Horton, J.D. Expression of SREBP-1c Requires SREBP-2-mediated Generation of a Sterol Ligand for LXR in Livers of Mice. eLife 2017, 6, e25015. [CrossRef]

40. Merath, K.; Chang, B.; Dubielzig, R.; Jeannotte, R.; Sidjanin, D.J. A spontaneous mutation in Srebf2 leads to cataracts and persistent skin wounds in the lens opacity 13 (lop13) mouse. Mamm. Genome 2011, 22, 661-673. [CrossRef]

41. Le Lay, K.S.; Farnier, C.; Lefrère, I.; Le Liepvre, X.; Bazin, R.; Ferré, P.; Dugail, I. Cholesterol, a cell size-dependent signal that regulates glucose metabolism and gene expression in adipocytes. J. Biol. Chem. 2001, 276, 16904-16910. [CrossRef] [PubMed]

42. Tremblay, F.; Perreault, M.; Klaman, L.D.; Tobin, J.F.; Smith, E.; Gimeno, R.E. Normal food intake and body weight in mice lacking the $G$ protein-coupled receptor GPR39. Endocrinology 2007, 148, 501-506. [CrossRef] [PubMed]

43. Ludgero-Correia, A., Jr.; Aguila, M.B.; Mandarim-de-Lacerda, C.A.; Faria, T.S. Effects of high-fat diet on plasma lipids, adiposity, and inflammatory markers in ovariectomized C57BL/6 mice. Nutrition 2012, 28, 316-323. [CrossRef] [PubMed]

44. Aamodt, K.I.; Powers, C.A. Signals in the pancreatic islet microenvironment influence $\beta$-cell proliferation. Diabetes Obes. Metab. 2017, 19 (Suppl. S1), 124-136. [CrossRef]

45. Bock, T.; Pakkenberg, B.; Buschard, K. Increased islet volume but unchanged islet number in ob/ob mice. Diabetes 2003, 52, 1716-1722. [CrossRef]

46. Hull, R.L.; Kodama, K.; Utzschneider, K.M.; Carr, D.B.; Prigeon, R.L.; Kahn, S.E. Dietary-fat-induced obesity in mice results in beta cell hyperplasia but not increased insulin release: Evidence for specificity of impaired beta cell adaptation. Diabetologia 2005, 48, 1350-1358. [CrossRef]

47. Peyot, M.-L.; Pepin, E.; Lamontagne, J.; Latour, M.G.; Zarrouki, B.; Lussier, R.; Pineda, M.; Jetton, T.L.; Madiraju, S.R.M.; Joly, E.; et al. Beta-cell failure in diet-induced obese mice stratified according to body weight gain: Secretory dysfunction and altered islet lipid metabolism without steatosis or reduced beta-cell mass. Diabetes 2010, 59, 2178-2187. [CrossRef]

48. Shah, S.; Yoon, G.H.; Chung, S.S.; Abid, M.N.; Kim, T.H.; Lee, H.Y.; Kim, M.O. Novel osmotin inhibits SREBP2 via the AdipoR1/AMPK/SIRT1 pathway to improve Alzheimer's disease neuropathological deficits. Mol. Psychiatry 2017, 22, 407-416. [CrossRef]

49. Xiao, X.; Song, B.L. SREBP: A novel therapeutic target. Acta Biochim. Biophys. Sin. 2013, 45, 2-10. [CrossRef]

50. Zheng, Z.; Zhang, X.; Zhou, Y.P.; Lu, C.; Thu, P.M.; Qian, C.; Zhang, M.; Li, P.; Li, H.J.; Xu, X. Anhydroicaritin, a SREBPs inhibitor, inhibits RANKL-induced osteoclastic differentiation and improves diabetic osteoporosis in STZ-induced mice. Eur. J. Pharmacol. 2017, 15, 156-162. [CrossRef]

Publisher's Note: MDPI stays neutral with regard to jurisdictional claims in published maps and institutional affiliations.

(C) 2020 by the authors. Licensee MDPI, Basel, Switzerland. This article is an open access article distributed under the terms and conditions of the Creative Commons Attribution (CC BY) license (http://creativecommons.org/licenses/by/4.0/). 